\title{
A IMPORTÂNCIA DA CIDADE DE MOSSORÓ NOS CENÁRIOS DO COMÉRCIO EXTERIOR BRASILEIRO E POTIGUAR
}

\author{
Marcelo Dantas Rosado Maia \\ Formado no curso superior de Tecnologia em Comércio Exterior pelo Instituto Federal de \\ Educação, Ciência e Tecnologia do RN. Estudante do curso superior de Direito pela \\ Universidade Federal do Rio Grande do Norte. Assistente Técnico Administrativo do \\ Ministério da Fazenda. E-mail: marcelorosado@uol.com.br \\ Elisângela Cabral de Meireles \\ Graduada em Ciências Econômicas-UFRN, esp. em Economia Regional, Comércio \\ Exterior e Globalização-UFRN, mestre em Administração (Gestão e Políticas Públicas) \\ UFRN , Professora do IFRN (Comércio Exterior e Economia) e Professora Orientadora da \\ Base de Pesquisa "Análise do Mercado Exportador do Rio Grande do Norte (IFRN). \\ E-mail- elisangela@cefetrn.br
}

\section{RESUMO}

A presente monografia tem como objetivo fundamental diagnosticar a importância da cidade de Mossoró nos contextos de comércio exterior do Brasil e do Rio Grande do Norte. Deste modo, faz-se necessária uma contextualização mundial acerca do ambiente em que está inserido o objeto de estudo, bem como um histórico sobre como se desenvolveu a economia mossoroense. Por motivo de pertinência, em relação à economia mossoroense, serão predominantemente abordadas as principais atividades econômicas sobre as quais se desenvolveu e, principalmente, que impulsionaram o grande crescimento recente da cidade. Para que o trabalho possa cumprir o que se propõe, a pesquisa efetuada é do tipo exploratório-descritiva, com pesquisas bibliográfica e documental, além da utilização de formulário utilizado em entrevistas direcionadas a gestores envolvidos na dinâmica do comércio internacional do Rio Grande do Norte, especialmente de Mossoró. Os dados, de ordem quantitativa e qualitativa, serão submetidos a avaliação subjetiva e crítica. De modo geral, espera-se, com a pesquisa, proporcionar ao leitor uma análise abrangente de como está posicionada a cidade de Mossoró no contexto do comércio exterior brasileiro e estadual, e, ainda, a capacidade de perceber futuras perspectivas acerca do desenvolvimento mossoroense sob essa óptica. O estudo concluiu, entre outras inferências, que a cidade tem importância fundamental para o comércio internacional do Rio Grande do Norte, figurando como principal pólo exportador do estado. No âmbito nacional, embora não represente parcela significativa em termos de valor exportado, a cidade se destaca em algumas atividades.

PALAVRAS-CHAVE: Mossoró, comércio internacional, crescimento econômico recente.

\section{THE IMPORTANCE OF THE CITY OF MOSSORO OVER BRAZILIAN AND RIO GRANDE DO NORTE'S INTERNATIONAL TRADE}

\begin{abstract}
The present monographic research has as its major objective to diagnose the importance of the city of Mossoró over Brazil's and Rio Grande do Norte's international trade. Therefore,
\end{abstract}


it becomes necessary to provide a worldwide context about the background in which the researched object is inserted, as well as a description about the way Mossoró's economy developed itself thorough history. For reasons of pertinence, in relation to the economy of Mossoró, the main economic activities which based the city's development and, specially, that pushed its recent development, will be mostly approached during this work. So that this project can provide what it intends to, the research is exploratory and descriptive, with documental and bibliographic researches, besides the utilization of a quiz used on interviews intended for managers involved in the city's international trade dynamics. The data, both quantitative and qualitative, will be submitted to a critic subjective evaluation. In a general way, it's expected, from this research, that it provides the reader a wide analyses of how the city of Mossoró is placed in the context of international trade of Brazil and Rio Grande do Norte, and, yet, the capacity to realize future perspectives about the city's development under this sight. The research concluded, among other things, that the city is very important to the international trade of Rio Grande do Norte, since it emerges as its main exporter center. In a national perspective, though it doesn't participate with a significant fraction of the exported amount, the city stands out in some activities.

KEY-WORDS: Mossoró, international trade, recent economic development.

\section{A IMPORTÂNCIA DA CIDADE DE MOSSORÓ NOS CENÁRIOS DO COMÉRCIO EXTERIOR BRASILEIRO E POTIGUAR}

\section{INTRODUÇÃO}

O estudo acerca da cidade de Mossoró, sob um ponto de vista preponderantemente econômico, tem o propósito principal de diagnosticar a sua importância para o comércio exterior do Brasil e do estado do Rio Grande do Norte.

Torna-se, desde já, evidentemente necessário avaliar de maneira breve o contexto em que se insere a cidade estudada.

Em primeiro plano, deve-se ter em mente a recente criação da OMC (Organização Mundial do Comércio), o contexto em que surgiu e as principais modificações que trouxe para os interesses brasileiros.

O cenário de surgimento da $\mathrm{OMC}$, e ainda atual, é marcado pela substituição do bilateralismo da Guerra Fria pelo multilateralismo no comércio mundial; pela globalização e interdependência das economias internacionais, com a intensificação do fluxo financeiro e comercial; pelo regionalismo e a formação dos blocos regionais; e pela atuação cada vez maior das empresas transnacionais.

Assim, é em um cenário de globalização ${ }^{1}$, em que o capital internacional busca cada vez mais alternativas de expansão, que está situada Mossoró. Nessa perspectiva, o fenômeno

\footnotetext{
${ }^{1}$ De acordo com Chesnais (1996, p. 24), o termo "mundialização do capital" reflete com mais precisão a substância do termo inglês original "globalization". Segundo o autor francês, tal fenômeno refletiria a capacidade estratégica dos grandes oligopólios em adotarem posturas ditas "globais". Assim, em síntese, a "globalização", ou "mundialização do capital" seria visto como o processo pelo qual o capital ganhou força a ponto de poder escolher (via liberalização e desregulamentação) para que direção iria se expandir.
} 
da globalização trouxe, a partir de meados do século passado, consequências que influíram incisivamente sobre o funcionamento das mais variadas economias regionais.

Sobre tal fenômeno, cumpre-se destacar que evidenciou-se pela promoção do liberalismo econômico e eliminação dos entraves ao fluxo internacional do capital.

Dessa forma, é notável a mudança provocada pela abertura econômica e da intensa liberalização do comércio exterior percebidas em função da mundialização sobre as economias brasileira, potiguar e mossoroense.

Importa também frisar que, em se tratando de uma cidade vista em um contexto global, deve-se necessariamente enxergá-la como "um local determinado em que estão ocorrendo processos globais" (SASSEN, 1998, p. 11).

Tratando especificamente da economia mossoroense, percebe-se que esta historicamente sempre desempenhou papel de destaque no estado, com especial realce para a atividade salineira, atividade petrolífera, fruticultura irrigada $\mathrm{e}$ indústrias de algodão e beneficiamento de castanha de caju.

Entretanto, é nos últimos anos que o crescimento da economia mossoroense e da sua participação no comércio exterior regional e nacional se dá com maior intensidade, com base principalmente em atividades tradicionais na região que conseguiram se fortalecer. Atualmente, têm-se ainda como principais atividades na pauta de exportações mossoroense a indústria salineira, o beneficiamento da castanha de caju e a fruticultura irrigada.

Cumpre destacar que este trabalho acadêmico foi construído com base em dados primários coletados por meio de entrevistas realizadas com gestores públicos e privados cujas atividades sejam relativas a Mossoró.

Deve-se fazer uma ressalva quanto a alguns dados que foram utilizados no decorrer do trabalho. As informações relativas ao período de janeiro a abril de 2007 , embora sejam úteis e não possam ser ignoradas, não permitem uma análise conclusiva, especialmente em alguns $\operatorname{casos}^{2}$, uma vez que, em um período tão curto, algumas variáveis não necessariamente ocorrentes durante todo o ano hão de ser consideradas.

É sabido, portanto, que a cidade de Mossoró desempenha tradicionalmente papel de suma importância na balança comercial do Rio Grande do Norte, tendo se destacado principalmente no decorrer dos últimos cinco anos.

Para se ter uma melhor noção deste crescimento recente, as exportações da cidade passaram de 36.192.871 (em US\$ FOB ${ }^{3}$ ), no ano de 2000, para 98.157.527 (em US\$ FOB), no ano de 2006, de acordo com o Ministério do Desenvolvimento, Indústria e Comércio Exterior. O que representa um significativo aumento de $271,2 \%$ no valor exportado em um período de seis anos.

\footnotetext{
${ }^{2}$ Como no caso da castanha de caju, analisado em momento oportuno.

${ }^{3}$ A sigla FOB se refere à cláusula inglesa Free on Board, segundo a qual, nos contratos de compra e venda internacionais, o vendedor não se responsabiliza pelos custos de frete e seguro. Os valores expressos em US\$ FOB, assim, são usualmente utilizados no comércio internacional para se referirem a valores líquidos.
} 
Da mesma forma, ainda de acordo com informações retiradas do site do Ministério, percebe-se que cinco das dez empresas que mais exportam do estado nos anos de 2005 e 2006 - em termos de valor negociado - são sediadas ou têm parte considerável de suas atividades estruturadas em Mossoró.

No ano de 2006, a propósito, Mossoró exportou cerca de US\$ 98 milhões, desbancando Natal, com aproximadamente US\$ 85 milhões, do primeiro lugar no ranking das cidades exportadoras do Rio Grande do Norte, ainda de acordo com informações do Ministério.

Em 2007, no período de janeiro a abril, Mossoró é também a cidade que mais exporta no estado, com mais de US\$ 33 milhões exportados, enquanto Natal exporta quase US\$ 21 milhões.

$\mathrm{Na}$ esfera nacional, de um total de US\$ 137.469.700.000 exportados pelo Brasil em 2006, Mossoró participou com US\$ 98.157.527, o que representa cerca de 0,07\% do todo.

Com efeito, o recente crescimento econômico experimentado por Mossoró não poderia passar desapercebido aos olhos da academia.

O que se pretende com este estudo, em linhas gerais, é possibilitar um maior entendimento, com respaldo teórico em alguns conceitos econômicos da atualidade, sobre os fatores que levam a cidade a se tornar confluência regional de recursos e atividades econômicas.

Afora a satisfação pessoal em trabalhar sobre universo amostral tão rico de informações e cercado de perspectivas otimistas, o tema concernente ao presente trabalho figura como da mais alta relevância.

Dessa forma, pretende-se, aqui, proporcionar ao leitor uma avaliação analítica e crítica das atividades e ações que levaram Mossoró à sua atual posição no cenário do comércio internacional do país e do estado; levando-o, portanto, a obter uma visão do atual estágio da economia mossoroense no que tange ao comércio exterior e, ainda, a ser capaz de elaborar expectativas futuras acerca da cidade.

Assim, em um contexto de globalização em que figuram o Brasil e, conseqüentemente, o Rio Grande do Norte e Mossoró, percebem-se o crescimento e a capacidade de inserção desta cidade em uma economia globalizada, com notáveis repercussões no âmbito regional. Diante do exposto, levanta-se como problema de pesquisa: qual a importância da cidade de Mossoró no âmbito do comércio internacional brasileiro e potiguar?

A problemática remete ao objetivo geral do trabalho, que consiste em diagnosticar a importância da cidade de Mossoró no comércio internacional do Brasil e do Rio Grande do Norte.

Para que seja alcançado, os seguintes objetivos específicos foram elaborados:

- Identificar e avaliar os fatores impulsionadores da economia mossoroense;

- Posicionar a economia mossoroense no cenário do comércio exterior;

- Avaliar as atividades que conferem à cidade sua atual posição no comércio internacional brasileiro e estadual; 
- Traçar perspectivas acerca do porvir da economia da cidade em termos de comércio internacional.

A definição da metodologia, por sua vez, orienta a realização de todo o trabalho pois, de acordo com Maia \& Oliveira (2005), os caminhos a serem percorridos, os métodos e as técnicas adotados na construção do trabalho científico são apontados desde já.

A pesquisa proposta possuiu caracteres exploratório e descritivo, uma vez que, com amparo na classificação adotada por Maia \& Oliveira (2005), enquanto a pesquisa exploratória busca uma aproximação com o tema por meio do levantamento de informações a ele concernentes, a pesquisa descritiva descreve as características do tema estudado, adicionando um caráter qualitativo ao projeto.

Dessa forma, além de se basear inicialmente em levantamento bibliográfico e documental, a pesquisa buscou, ainda, observar, analisar e interpretar os dados coletados.

O universo da pesquisa foi o conjunto de gestores, sejam eles públicos ou privados, do município de Mossoró, situado no estado do Rio Grande do Norte. Do universo, a amostra a ser estudada abrangeu um grupo constituído de dez indivíduos, dentre eles: ícones do empresariado local capazes de representá-lo de maneira satisfatória e pessoas ligadas à gestão pública municipal.

Vale salientar que a amostra utilizada não foi probabilística, obedecendo a parâmtros de escolha subjetivos, baseados em critérios de conveniência e oportunidade.

Além de pesquisa bibliográfica, o presente estudo contou com pesquisa documental e, como instrumento de coleta de dados de ordem primária, a elaboração de formulários utilizados em entrevistas direcionadas a empresários e pessoas da gestão pública da cidade de Mossoró.

Os formulários, notadamente semi-abertos, contidos nos apêndices infraexpostos, buscaram obter dos gestores sua apreciação acerca de aspectos da importância da economia mossoroense no comércio internacional.

A estrutura dos formulários foi elaborada de modo a obter, em um primeiro momento, dados relativos à atividade do entrevistado no cenário da economia mossoroense (para os gestores privados). Em seguida, buscou-se obter dos entrevistados informações gerais sobre as atividades que, em sua visão, se destacam no comércio exterior da cidade.

Os formulários passaram ainda por questionamentos acerca da atuação governamental relativa à economia, com especial foco no tocante ao comércio internacional.

Por fim, procurou-se alcançar dos entrevistados suas expectativas sobre o futuro da economia da cidade, mais especificamente sobre as atividades relacionadas ao comércio internacional.

As informações obtidas de ordem primária, orientando-se para a satisfação do problema de pesquisa, consistiram predominantemente em dados qualitativos. Estes, aliados aos dados quantitativos obtidos em fontes secundárias documentais e bibliografia, foram submetidos à análise subjetiva de modo a esclarecer as questões pretendidas. 


\section{CONTEXTUALIZAÇÃO ECONÔMICA E HISTÓRICA: ASPECTOS GLOBAIS E LOCAIS PERTINENTES À CIDADE DE MOSSORÓ}

Primeiramente, deve-se abordar, para fins de embasamento teórico, o contexto internacional que envolve o processo de criação da OMC e que ainda se faz notar nos dias de hoje.

O primeiro fator a ser analisado da atual conjuntura internacional é o fim do bipolarismo nas relações internacionais e sua substituição por um modelo multipolar.

À época da Guerra Fria, a organização internacional das nações se dava pela presença de um bem definido sistema bipolar que contava com as lideranças antagônicas de EUA e URSS. Com a queda do muro de Berlim, todavia, os EUA passaram a se impor como maior potência militar e econômica.

O comércio, por sua vez, passou a ter um conjunto de grandes potências - EUA, Comunidade Européia, Japão e China. Assim, "a principal conseqüência para o comércio internacional é a de que os EUA perderam o papel de árbitro das regras do comércio, deixando espaço para um clima de contantes conflitos com outras potências econômicas" (THORSTENSEN, 2001, p. 22).

No contexto do multilateralismo, segundo o qual teoricamente todos devem ter espaço no comércio internacional, surge, entretanto, a tendência contraditória do regionalismo. Dessa forma, passam a fazer parte do comércio internacional, em número cada vez maior, os blocos regionais.

Nesse meio, Thorstensen (2001) aponta que os países se encontram no dilema de aderirem ou não a esses acordos e, no caso de já participarem de algum bloco, devem optar entre a "deep integration" 4 e a "shallow integration" 5 .

Deve-se também ressaltar a importância das empresas transnacionais no comércio exterior. $\mathrm{O}$ que se destaca sobre elas é que influenciam diretamente nos mercados em que atuam, estando por vezes fora do controle dos governos, e criam grandes distorções na especialização das exportações por país e por produto, uma vez que causam o chamado comércio intra-indústria, caracterizado pela incidência de importações e exportações dentro do mesmo setor industrial.

Acrescenta-se a isso, ainda de acordo com Thorstensen (2001), o cenário de interdependência econômica e a globalização das economias, que, aliada a um enorme avanço na tecnologia da informação, trouxe drástica aceleração dos fluxos de comércio e de investimento.

\footnotetext{
${ }^{4}$ Estratégia de aprofundamento dos esquemas existentes entre os países participantes do bloco. Thorstensen (2001) aponta quatro tipologias de acordos regionais: zona de livre comércio, união aduaneira, mercado comum e união monetária. A tipologia varia de acordo com o nível de integração percebido.

${ }^{5}$ Estratégia de alargamento do número de países participantes do bloco.
} 
Assim, dentro de todo esse cenário acima descrito, surgiu a OMC, órgão de grande relevância para o comércio internacional atual e que acumula a importante função de árbitro de questões comerciais internacionais.

Importante frisar que a OMC surgiu em decorrência do GATT (General Agreement on Tariffs and Trade). O GATT, segundo Maia (2003), foi um acordo multilateral sobre comércio internacional assinado em Genebra, em 1947, que apresentava alguns princípios básicos, pelos quais o comércio deveria ser conduzido de forma não discriminatória, não deveriam ser utilizadas quaisquer restrições quantitativas ao comércio, e as disputas comerciais internacionais deveriam ser resolvidas por meio de consultas.

De um modo geral, Luz (2006) aponta que as funções da OMC consistem em: facilitar a aplicação, administração e funcionamento de uma série de $\operatorname{Acordos}^{6}$ Comerciais Multilaterais e determinados Acordos Comerciais Plurilaterais; servir como órgão de apoio aos países que necessitarem de consultas e assessorias concernentes ao comércio internacional; administrar as controvérsias surgidas; fiscalizar políticas comerciais dos países-membros; e atuar em conjunto com o FMI e o BIRD.

Thorstensen (2001) afirma ainda que, para o Brasil, de forma simplificada, a Rodada Uruguai $^{7}$, que criou a $\mathrm{OMC}$, foi considerada satisfatória, uma vez que seus principais objetivos foram alcançados. $\mathrm{Na}$ área da agricultura, embora ainda se tenha muito a demandar em futuras rodadas, a Rodada Uruguai trouxe reduções tarifárias dos países desenvolvidos sobre produtos tropicais de até $40 \%$.

Maia (2003) aponta que a Rodada Uruguai derrubou mais barreiras que qualquer outro na História, além de trazer reduções tarifárias benéficas a diversos produtos brasileiros.

\section{GLOBALIZAÇÃO E MUNDIALIZAÇÃO}

Embora se utilize amplamente a denominação "Globalização" para se referir ao termo original globalization, um olhar mais atento sobre o tema leva à conclusão obtida por Chesnais (1996) de que a expressão mais adequada substancialmente ao que a globalization alude seria a "mundialização do capital".

O mesmo autor destaca que a "Mundialização do capital" reflete a idéia de que o capital, favorecido pelas políticas de liberalização surgidas no fim da década de 70 e amplamente impostas nos anos seguintes, passou a ter o poder de escolher em que direção iria se expandir.

\footnotetext{
${ }^{6}$ Para Maia (2003), acordos são, assim como os tratados, acertos firmados entre determinadas nações pelo qual se estabelecem certos objetivos e períodos de vigência. Os acordos, a seu ver, seriam uma das forças positivas que estimulam e engrandecem a Economia Internacional.

7 Negociação multilateral iniciada em 1986, na cidade de Punta del Leste. Dentre outros temas, a Rodada Uruguai abordou a criação da OMC; o rebaixamento tarifário para produtos industriais e produtos agrícolas; introdução de novos setores para o quadro do GATT e liberalização dos mesmos: agricultura, têxteis, serviços e propriedade intelectual; reforço das regras do GATT em temas como anti-dumping, subsídios, salvaguardas, etc.; negociação de um novo processo de solução de controvérsias; prazos de implantação dos temas negociados.
} 
Brum (2003) afirma que a globalização se expande a partir da aceleração da integração espacial mundial e da cada vez mais livre circulação de capitais financeiros, investimentos, mercadorias e tecnologias.

O mesmo autor aponta que "nessa nova etapa do capitalismo, as mudanças são impulsionadas, principalmente, pela inovação tecnológica permanente, pelo avanço das telecomunicações, pela internacionalização financeira, do processo produtivo e do consumo, pela industrialização da cultura, pela desregulação e abertura das economias, pela liberalização e ampliação dos mercados” (BRUM, 2003, p. 74).

Infere-se, de acordo com Chesnais (1996), que o termo "Globalização", acompanhado de outros termos vagos, como "tecno-globalismo" e mundo "sem fronteiras", são imposições do interesse do capital, de modo que sejam ocultados os malefícios da mundialização.

Dessa forma, ao contrário do termo "Globalização", a "Mundialização" sugere mais explicitamente a necessidade da criação de instituições voltadas para o controle de uma economia mundializada.

Pode-se afirmar, com base em Chesnais (1996), sobre a Mundialização, que esta resultou de dois processos interligados. Primeiramente, de uma longa fase de acumulação de capital, desde 1914. E, ainda, das políticas de liberalização, privatização, desregulamentação e desmantelamento de conquistas sociais e democráticas aplicadas intensamente pelos governos Tatcher e Reagan.

O processo de Mundialização viabilizou o fluxo financeiro de maneira mais livre. Isso, ao mesmo tempo em que trouxe grandes transformações no comércio internacional, gerou também grandes distorções. Assim, tendo em vista que o capital escolhe qual rumo tomar, este se torna excludente.

Luz (2006) argumenta que, embora a globalização possibilite, pela integração mundial, melhor alocação dos fatores produtivos, tem o aspecto negativo de aumentar o grau de interdependência entre os países, fazendo com que uma crise local tenha repercussões globais. Além, disso, aponta o autor, a globalização traz ainda a alta instabilidade dos fluxos financeiros, que - seguindo a perspectiva de capital excludente proposta por Chesnais - podem ser cortados em caso de risco de perda de rentabilidade.

\section{AS CIDADES NA ECONOMIA INTERNACIONAL}

A visão sociológica que orientava as análises feitas sobre as cidades não basta para a compreensão do modo como as cidades se portam diante do fenômeno de mundialização atual.

Desse modo, a cidade passa a ser vista como um determinado espaço onde ocorrem processos globais.

De acordo com Levy (1997, p. 33), a "globalização tem determinado uma nova hierarquia de espaços, o aparecimento de novas funções desempenhadas em novos locais, e a reconfiguração física, econômica e social dos espaços existentes”. Sob essa perspectiva, 
afirma a autora que as cidades resultam da ação de atores econômicos e políticos, nacionais e globais.

Assim, percebe-se que a cidade, inserida no contexto da globalização, assume novas atribuições.

$\mathrm{Na}$ economia global, conforme pensamento de Sasken (1998), a dispersão das atividades econômicas relativizam a importância do lugar para a produção. $O$ grande desenvolvimento das telecomunicações possibilita a administração remota e, por meio de uma grande realocação de escritórios e fábricas em locais menos congestionados, poderia estar próximo o fim dos grandes centros urbanos.

Entretanto, há uma nova tendência de centralização, em torno de uma cidade, do gerenciamento no nível dos altos escalões e do controle das operações.

Sobre isso, Sasken (1998, p. 13), afirma que "os mercados nacionais e globais, bem como as operações globalmente integradas, requerem lugares centrais, onde se exerça o trabalho de globalização".

Tal centralização se dá em torno das chamadas "cidades globais", que, segundo a referida autora, se caracterizam por constituírem pontos de comando na organização da economia mundial; serem lugares e mercados fundamentais para as principais indústrias da atualidade, ou seja, as finanças e os serviços especializados destinados às empresas; e por consistirem em lugares de produção fundamentais para estas indústrias, com a produção de inovações.

Percebe-se, ainda, que esta centralização pode se dar em escalas geográficas inferiores, em torno de cidades menores que centralizam atividades no âmbito regional.

Nessa perspectiva, as cidades globais poderiam ser definidas, nas palavras de Sasken (1998, p. 35), como "os lugares-chaves para os serviços avançados e para as telecomunicações necessárias à implementação e ao gerenciamento das operações econômicas globais".

Assim, é possível afirmar, ainda de acordo com Sasken (1998, p.156), que, no contexto da economia global, "as cidades são lugares estratégicos que concentram funções de comando, mercados globais e (...) são locais de produção para as indústrias corporativas de prestação de serviços".

\section{ABORDAGEM HISTÓRICA DA ECONOMIA MOSSOROENSE}

A cidade de Mossoró passou a se destacar economicamente no estado a partir do ano de 1857, quando, segundo Rocha (2004), a Companhia Pernambucana de Navegação Costeira começou a fazer escala normal no porto de Mossoró (hoje pertencente ao município de Areia Branca).

A partir deste fato, a cidade sofreu grandes mudanças, deixando de ser sua economia essencialmente agro-pastoril para se tornar, conforme apontamento de Rocha (2004, p. 29), 
em empório comercial, "o lugar da comercialização, da troca e do abastecimento entre o sertão e o litoral".

Após muitos anos de prosperidade e transações de produtos no âmbito regional, o empório comercial de Mossoró, em virtude do atraso da implementação de uma ferrovia, do fortalecimento da praça de Campina Grande e do surgimento de novas redes de intercâmbio comercial, entrou em crise que iria transformar completamente a economia da cidade.

Assim, no início do século XX, com a acumulação de capital auferida ainda no tempo do empório, a cidade pôde se voltar para o beneficiamento de produtos extrativos, como carnaúba e oiticica e produtos agrícolas, como algodão e algave. O "semibeneficiamento" destas matérias-primas abastecia as indústrias de São Paulo.

A industrialização da cidade, portanto, esteve durante boa parte do século XX ligada a essas atividades agropecuárias. A queda das agroindústrias ocorreu em meados da década de 1960, ainda de acordo com Rocha (2004), devido ao surgimento das fibras sintéticas, em substituição às de carnaúba e algodão; à mecanização das salinas; à restrição do mercado para óleo de algodão em razão do cultivo de soja no Sul e Sudeste do Brasil; e à substituição da oiticica e da cera por esmaltes e outros derivados do petróleo.

Face a uma nova Divisão Internacional do Trabalho e à resistência à utilização de novas tecnologias no processo produtivo, as agroindústrias entraram em crise e deram lugar a novas atividades.

A atividade salineira, por sua vez, passou a sofrer a partir do surto industrializante que se percebia no Brasil, promovido pelo governo Juscelino Kubitschek, pela sua defasagem em relação ao resto do país.

Com o desenvolvimento da indústria química nacional e sua crescente demanda por sal, a indústria salineira de Mossoró se encontrou forçada a se modernizar e passou pelo que ficou conhecido nacionalmente como "modernização dolorosa".

Brum (2003, p. 244) afirma, sobre o processo de industrialização brasileira no período do governo de Juscelino Kubitschek, que "as empresas multinacionais foram assumindo o controle dos ramos de ponta da indústria de bens duráveis (...), ao mesmo tempo que consolidavam uma posição de destaque nas indústrias farmacêutica, naval, de material e equipamento elétrico, mecânica pesada".

Seguindo na linha desenvolvida por Rocha (2004), como boa parte das empresas salineiras não tinha capital para se mecanizar, muitas salinas (cerca de 44\%) foram compradas por grupos econômicos internacionais. As demais se agruparam em grupos regionais, de modo que, de capital nacional ou internacional, as salinas de modo geral se tornaram grandes unidades produtivas com alto poder de acumulação.

$\mathrm{Na}$ atualidade, $95 \%$ da produção nacional de sal vem do Rio Grande do Norte. O estado, de acordo com Souto \& Fernandes (2005), tem características de ordem morfológica, climática e geográfica bastante favoráveis à atividade salineira. Os autores destacam que o clima semi-árido com longa estação seca, as altas temperaturas e os baixos índices 
pluviométricos, aliados à ocorrência de sal no estuário do rio Mossoró tornaram viável a exploração da atividade salineira na região.

No âmbito internacional, embora a indústria salineira passe por algumas dificuldades, cujas principais causas apontadas variam entre a concorrência do sal chileno até um problema logístico de incapacidade de distribuição de todo o sal produzido, o sal continua sendo um dos principais produtos exportados pela cidade.

O petróleo, de história bem mais recente na região, teve sua extração em Mossoró iniciada no ano de 1980, com a chegada definitiva da Petrobrás.

Para Rocha (2004, p. 109), com a sua instalação, "dezenas de outras empresas prestadoras de serviços no ramo petrolífero também chegaram à Cidade, por causa do início e da intensificação das atividades de exploração de petróleo".

Além destas, outras tantas tiveram que surgir como forma de atender àquela oferta de trabalhadores que chegava com elas. Assim, desenvolveram-se na cidade empresas de hotelaria, construção civil, alimentação, entre muitas outras.

Essa chegada de grande número de empresas trouxe a necessidade imediata de grandes investimentos em infra-estrutura, levando Mossoró a sensíveis modificações no seu espaço urbano.

Atualmente, o Rio Grande do Norte responde pela maior produção terrestre de petróleo do Brasil, tendo Mossoró o maior número de poços em produção no estado.

Rocha (2004, p. 127) afirma, sobre o início da exploração petrolífera, que "desde a sua implantação no Rio Grande do Norte, a Companhia vem investindo uma massa considerável de recursos em Economia do Estado, sob a forma de impostos, taxas, royalties pagos ao Estado e aos Municípios, indenizações aos proprietários de terras, compras de bens e serviços, investimentos, massa salarial, entre outros".

Mossoró, face à sua produção, está entre os municípios que mais recebem recursos oriundos da Petrobrás, o que potencializa vertiginosamente sua capacidade de investimento.

Assim, quando se trata de pauta de exportações do estado, cumpre dizer que os óleos brutos de petróleo tem figurado sucessivamente entre os mais exportados (em valor) nos últimos anos.

Todavia, percebe-se, de acordo com a Tabela 1, que as exportações de óleos brutos de petróleo vêm decaindo desde 2005, chegando à estagnação em 2007.

Tabela 1 - Exportações de Óleos Brutos de Petróleo De 2005 a 2007.

Ano

Exportações de Óleos Brutos de Petróleo (em US\$ FOB)

2005

96.870 .955

2006

27.933 .228

2007

0

Fonte: Ministério do Desenvolvimento, Indústria e Comércio Exterior (2007). 
Por último, torna-se necessária uma breve explanação histórica também sobre a fruticultura irrigada.

Diz-se que, aliada à salinicultura e à exploração de petróleo, completa o tripé de sustentação econômica de Mossoró.

A modernização agroindustrial por que passou o Rio Grande do Norte tem início na década de 1960, por meio dos programas federais de desconcentração do processo de geração de riquezas no Brasil. Embora se tenha inicialmente pretendido desenvolver os chamados Complexos Agroindustrais Brasileiros, Rocha (2004, p. 134) ressalva que a modernização da agricultura do país assumiu "expressão concreta em áreas espacialmente restritas e pontuais”, como em Mossoró e Açu.

A mesma autora afirma que "em meados dos anos 1960, desenvolveu-se no Brasil uma Política Agrícola com a orientação de intensificar a interação entre Agricultura, a Indústria de Bens de Capital e a Indústria de Processamento" (ROCHA, 2004, p. 134). Pretendia-se, portanto, dar um caráter mais industrial à agricultura, pela forma que era praticada naquele momento.

O processo de industrialização pretendido pelo governo federal trouxe diversos programas de incentivo à agroindústria no Nordeste. A partir do Programa de Integração Nacional, o Departamento Nacional de Obras Contras as Secas (DNOCS) investiu maciçamente em perfuração de poços, construção de açudes e perímetros irrigados.

Em 1968, o Grupo Executivo de Irrigação para o Desenvolvimento Agrícola (GEIDA) definiu uma política de irrigação para o Nordeste. A partir dele, uma série de programas, planos e projetos se seguiram pelas últimas quatro décadas, geralmente voltados para infraestrutura, pesquisa tecnológica e crédito agrícola.

A partir da década de 1970, como destaca Rocha (2004), com a atuação da Companhia do Desenvolvimento do Vale São Francisco (CODEVASF), as ações governamentais se voltam para vários programas de irrigação, com a implantação dos Perímetros Públicos Irrigados.

O GEIDA, na década de 1970, realizou vários estudos para viabilizar a implantação dos programas de irrigação pretendidos. Rocha (2004) constata que, com acesso às informações sobre quais áreas seriam favorecidas com a irrigação, muito investiram na sua aquisição, o que contribuiu para a concentração das terras irrigadas.

Destaca-se, entre os programas, o Programa de Desenvolvimento de Áreas Integradas do Nordeste (POLONORDESTE), que, com a finalidade de promover o desenvolvimento e a modernização das atividades agropecuárias em áreas prioritárias do Nordeste, contemplou o Vale dos rios Piranhas/Açu e Apodi/Mossoró.

As ações governamentais direcionadas para a agricultura irrigada resultaram na implantação, pelo DNOCS, de quatro perímetros irrigados no estado, os chamados Projeto Cruzeta, Projeto Itans-Sabugi (os dois hoje em dia completamente abandonados), Projeto Pau dos Ferros e o Projeto Baixo-Açu. 
Atualmente, os lotes nos perímetros formam grandes áreas de produção privada, embora a intenção dos programas tenha sido inicialmente "forjar um grande contingente de irrigantes entre os pequenos produtores locais" (ROCHA, 2004, p. 140).

De um modo geral, Rocha (2004, p.144) conclui que "as políticas governamentais implementadas para o Pólo de Mossoró ajudaram a implantar e consolidar a Agricultura Irrigada em Mossoró, com a isenção de impostos, intervenção no Mercado de Terras com favorecimentos das empresas de maior porte, ou com Infra-Estrutura".

A mesma autora aponta que na década de 1990, notadamente no governo Fernando Henrique Cardoso, vários programas de desenvolvimento - dentre eles o "Iniciativa pelo Nordeste", o "Programa de Apoio e Desenvolvimento sa Fruticultura Irrigada do Nordeste" e o "Projeto Pólos de Desenvolvimento Integrado", com forte apoio à iniciativa privada, possibilitaram uma contínua renovação de suas forças produtivas.

Esses programas, assim como os anteriores, preconizavam pela modernização da agroindústria. E Mossoró, desde o início, sempre se mostrou bastante receptivo às modernizações propostas, ainda conforme Rocha (2004, p. 148), com "índices de difusão de inovações dificilmente comparáveis aos de outras áreas”.

Atualmente, Mossoró é referência nacional em termos de modernização do processo produtivo da agricultura irrigada. Desde a década de 1970, a partir da implantação da Mossoró Agroindustrial S/A (MAISA), a cidade se tornou um pólo da produção de frutas tropicais no país.

Tabela 2 - Principais Produtos Exportados pelo Rio Grande do Norte em 2006.

\begin{tabular}{|c|c|c|c|}
\hline & Principais Produtos Exportados & $\begin{array}{l}\text { Valor (US\$ } \\
\text { FOB) }\end{array}$ & $\begin{array}{l}\text { Quantidade } \\
(\mathrm{Kg})\end{array}$ \\
\hline 1 & MELOES FRESCOS & 58.117 .140 & 115.757 .843 \\
\hline 2 & CASTANHA DE CAJU,FRESCA OU SECA,SEM CASCA & 45.565 .007 & 10.440 .284 \\
\hline 3 & CAMAROES,INTEIROS,CONGELADOS,EXCETO "KRILL" & 41.052 .100 & 10.289 .646 \\
\hline 4 & OLEOS BRUTOS DE PETROLEO & 27.933.228 & 72.332 .872 \\
\hline 5 & BANANAS FRESCAS OU SECAS & 24.579 .774 & 84.104 .977 \\
\hline 6 & $\begin{array}{l}\text { ALCOOL ETILICO N/DESNATURADO C/VOL.TEOR } \\
\text { ALCOO }\end{array}$ & 24.007.072 & 41.374 .868 \\
\hline 7 & $\begin{array}{l}\text { OUTS.ACUCARES DE CANA,BETERRABA,SACAROSE } \\
\text { QUIM }\end{array}$ & 22.511 .900 & 63.000 .000 \\
\hline 8 & CONSUMO DE BORDO - COMBUSTIVEIS E LUBRIF.P/AE & 12.671 .036 & 14.781 .226 \\
\hline 9 & SAL MARINHO,A GRANEL,SEM AGREGADOS & 9.682 .808 & 747.567 .141 \\
\hline 10 & BOMBONS,CARAMELOS,CONFEITOS E PASTILHAS & 8.096 .104 & 7.636 .112 \\
\hline
\end{tabular}

Fonte: Ministério do Desenvolvimento, Indústria e Comércio Exterior (2007).

No cenário do comério internacional atual, a agricultura irrigada de Mossoró se destaca por ter produtividade compatível com países desenvolvidos e volta sua produção para o mercado externo, de modo que surge na balança comercial do estado com alguns dos principais produtos exportados, como se vê na Tabela 2. 
A importância da fruticultura irrigada para a economia do estado é notável; três dos cinco principais produtos exportados pelo estado em 2006, de acordo com a tabela acima, são relacionados a essa atividade, que representou, naquele ano, quase $40 \%$ do total de US\$ FOB 371.503.239 exportados pelo Rio Grande do Norte.

De fato, em grande parte pelas exportações de melão e castanha de caju, Mossoró é atualmente o principal pólo exportador do estado, como se vê na tabela abaixo.

Tabela 3 - Principais Municípios Exportadores do Rio Grande do Norte em 2006.

\begin{tabular}{cc}
\hline Municípios & Valor Total Exportado (US\$ FOB) \\
\hline Mossoró & 98.157 .527 \\
Natal & 85.382 .746 \\
Macaíba & 36.237 .395 \\
Ipanguaçu & 25.899 .609 \\
Baía Formosa & 25.007 .176 \\
Arês & 24.305 .447 \\
Canguaretama & 13.812 .801 \\
Parnamirim & 10.834 .672 \\
Pendências & 9.719 .436 \\
São Gonçalo do Amarante & 7.536 .581 \\
\hline
\end{tabular}

Fonte: Ministério do Desenvolvimento, Indústria e Comércio Exterior (2007).

A tabela acima já coloca a cidade em primeiro lugar no ranking dos municípios exportadores do estado. O fato é da maior relevância, tendo em vista que a capital Natal sempre teve historicamente maior destaque nas exportações potiguares.

De um total de mais de US\$ 371 milhões exportados pelo Rio Grande do Norte, o município de Mossoró, de acordo com a Tabela 3, exportou cerca de US\$ 98 milhões, o que representa uma parcela de aproximadamente $26,4 \%$, ou seja, mais de um quarto das exportações estaduais.

As exportações de melão já apresentam grande crescimento no primeiro terço de 2007 , com um aumento de $44,8 \%$ em relação ao valor exportado do mesmo período do ano passado.

Embora a castanha de caju apresente queda da ordem de 40,53\% do valor exportado no período de janeiro a abril de 2007 em comparação com o mesmo período de 2006, deve-se frisar que essa situação tende a ser passageira. A queda da cotação do dólar foi decisiva para esse decréscimo, causando uma momentânea estocagem de produtos. Dessa forma, os dados do início de 2007 ainda não podem ser vistos como representativos de todo o ano. 
Tabela 4 - Principais Produtos Exportados por Mossoró em 2006.

\begin{tabular}{llc}
\hline \multicolumn{1}{c}{ Principais Produtos Exportados } & \multicolumn{1}{c}{$\begin{array}{c}\text { Valor (US\$ } \\
\text { FOB) }\end{array}$} & $\begin{array}{c}\text { Quantidade } \\
(\mathrm{Kg})\end{array}$ \\
\hline 1 MELOES FRESCOS & 48.758 .289 & 94.514 .501 \\
2 CASTANHA DE CAJU,FRESCA OU SECA,SEM CASCA & 39.600 .986 & 8.954 .155 \\
3 MELANCIAS FRESCAS & 3.523 .296 & 9.766 .986 \\
4 SAL MARINHO,A GRANEL,SEM AGREGADOS & 2.292 .344 & 180.866 .941 \\
5 CERAS VEGETAIS & 1.550 .474 & 544.600 \\
6 CAMAROES,INTEIROS,CONGELADOS,EXCETO "KRILL" & 1.152 .807 & 305.560 \\
7 MEL NATURAL & 631.863 & 438.749 \\
8 OUTS.FRUTAS DE CASCA & 269.875 & 72.576 \\
RIJA,OUTS.SEMENTES,PREPARS/CONSERV & 132.185 & 593.590 \\
9 SUCOS E EXTRATOS,DE OUTROS VEGETAIS & 62.024 & 164.784 \\
\hline 10OUTROS PRODS.HORTICOLAS,FRESCOS OU REFRIGER. & & \\
\hline
\end{tabular}

Fonte: Ministério do Desenvolvimento, Indústria e Comércio Exterior (2007).

Acima, a Tabela 4 confirma o grande destaque da fruticultura irrigada e da castanha de caju na conjuntura econômica da cidade, ocupando os primeiros lugares no elenco dos seus principais produtos exportados.

Outros produtos, todavia, embora tenham características e diferentes trajetórias na história da economia local, apresentam também relativa importância no cenário mossoroense.

São os casos da cera de carnaúba e do mel natural de abelha. O primeiro, segundo Rocha (2005, p. 46), teve grande importância a partir da primeira metade do século XX, com o estabelecimento de agroindústrias que beneficiavam alguns produtos, entre eles a carnaúba, para indústrias de óleos e derivados, onde eram "semibeneficiados" e comercializados como matéria-prima para indústrias do Sudeste, principalmente de São Paulo.

Rocha (2005, p. 55), conclui, contudo, que, com o desenvolvimento tecnológico de outras indústrias do país, que fizeram surgir as fibras sintéticas e alguns derivados da química do petróleo, os produtos derivados da carnaúba restaram obsoletos e as agroindústrias que faziam seu beneficiamento entraram em declínio.

$\mathrm{Na}$ atualidade, entretanto, a cera de carnaúba passa a readquirir alguma importância, com base em novas utilizações de suas propriedades.

O mel natural de abelha, por seu turno, representa novas atividades que surgem no comércio exterior mossoroense. 
Tabela 5 - Exportações Mossoroenses de Mel e Camarão de Janeiro a Abril de 2007 e de 2006.

\begin{tabular}{ccccc}
\hline & \multicolumn{2}{c}{2007} & \multicolumn{2}{c}{2006} \\
\hline Produtos & $\begin{array}{c}\text { Valor (US\$ } \\
\text { FOB) }\end{array}$ & $\begin{array}{c}\text { Quantidade } \\
(\mathrm{Kg})\end{array}$ & $\begin{array}{c}\text { Valor (US\$ } \\
\text { FOB) }\end{array}$ & $\begin{array}{c}\text { Quantidade } \\
(\mathrm{Kg})\end{array}$ \\
MEL NATURAL & 105.858 & 76.571 & 0 & 0 \\
$\begin{array}{c}\text { CAMAROES,INTEI } \\
\text { ROS, }\end{array}$ & 0 & 0 & 742.191 & 196.420 \\
$\begin{array}{c}\text { CONGELADOS,EX } \\
\text { CETO "KRILL" }\end{array}$ & & & & \\
\hline
\end{tabular}

Fonte: Ministério do Desenvolvimento, Indústria e Comércio Exterior (2007).

Na tabela acima, dois dos principais novos produtos constantes na pauta de exportações da cidade: a apicultura, que começa a surgir recentemente na economia da cidade; e o camarão, que passa por crise oriunda principalmente de taxação imposta ao camarão brasileiro pelo governo dos E.U.A., da queda brusca do dólar, do surgimento de pragas e da falta de apoio governamental, conforme informações veiculadas pela Secretaria de Estado do Meio Ambiente e dos Recursos Hídricos.

\section{ANÁLISE DOS RESULTADOS}

Os dados primários - cuja obtenção fora previamente apontada - foram alcançados por meio de dez entrevistas baseadas em formulários (apêndices A e B) direcionados a gestores da iniciativa privada (formulário 1) e gestores públicos (formulário 2). Do total de dez entrevistados, foram sete da iniciativa privada e três gestores públicos.

Dentre a amostragem, foram escolhidos representantes dos setores de petróleo, metal mecânico, apicultura, beneficiamento de castanha de caju, sal e fruticultura irrigada, além de representantes da administração pública, tanto na esfera municipal quanto na estadual.

Os formulários, de um modo geral, pretenderam obter dos entrevistados suas visões sobre a economia mossoroense, com especial atenção às atividades voltadas para o mercado externo.

Assim, prezando pelo aspecto subjetivo dos dados, os entrevistados foram solicitados a apontar atividades consolidadas voltadas ao mercado externo, avaliar a atuação do governo no tocante a políticas públicas referentes ao comércio exterior, indicar potenciais econômicos da cidade, além de prestar outras opiniões.

Em ampla perspectiva, tanto empresariado quanto gestores públicos se mostraram otimistas e satisfeitos com o desempenho mossoroense no comércio internacional.

Todos apontaram números variáveis entre três e cinco quando questionados sobre quantas atividades se destacam no comércio internacional na economia local. Os entrevistados unanimemente citaram fruticultura, petróleo e sal. 
De fato, percebe-se, pela análise da Tabela 2, que frutas, castanha de caju, petróleo e sal são atualmente produtos de grande relevância na balança comercial potiguar.

Em relação ao setor de fruticultura, as razões apontadas para o seu bom desempenho foram principalmente a alta qualidade da fruta, as condições climáticas da região e a consolidação dos produtores locais no mercado externo, decorrente de contatos estabelecidos há muito tempo e responsabilidade contratual.

A qualidade dos produtos da fruticultura mossoroense vem crescendo há anos e é devida a uma série de técnicas utilizadas no processo produtivo, como, por exemplo, o gotejamento ${ }^{8}$ e a fertirrigação ${ }^{9}$.

São apontados também investimentos em infra-estrutura por parte do empresariado. Nos últimos dez anos, o número de empresas com estrutura de frio completa passou de três para dez, com investimento de cerca de US\$2 milhões.

Os aspectos naturais são, na visão dos gestores entrevistados, quase ideais para a fruticultura irrigada. Para o empresariado, a alta incidência solar ${ }^{10}$ aliada aos baixos índices pluviométricos peculiares à região são propícios à produção.

Na prática, essas condições refletem na redução temporal do processo produtivo. Na região de Mossoró, o período entre plantio e colheita de melão dura cerca de 60 dias, enquanto na Espanha, por exemplo, chega a durar 120 dias. Torna-se possível, assim, a produtividade de 2,5 safras por ano (contra 1,5 safras por ano na Califórnia - EUA).

As condições climáticas peculiares da região proporcionam ao produtor um período de sazonalidade em que há grande demanda principalmente de melão no mercado externo. Entre 15 de setembro e 15 de janeiro, a produção mossoroense se aproveita da entre-safra dos produtores de melão de outros países, sendo momentaneamente a única área produtora de melão do mundo.

O óleo bruto de petróleo, também citado pelos entrevistados como um dos produtos de destaque no comércio internacional mossoroense, teve recentemente grande relevância na balança comercial do estado; contudo, não é mais destinado ao mercado externo.

Tal se deve, conforme observação feita por gestores públicos entrevistados, pelo fato de ter sido ampliada a capacidade das refinarias nacionais, em especial a Refinaria Landulpho Alves, na Bahia, que recebe a maior parte do óleo produzido no Rio Grande do Norte. Assim, não há necessidade de exportar o óleo bruto, de menor valor agregado, uma vez que era exportado por não haver capacidade instalada no país para refinar todo o óleo produzido.

\footnotetext{
${ }^{8} \mathrm{O}$ gotejamento consiste em sistema de irrigação originária de Israel por meio do qual a água é transportada gota a gota sobre ou sob o solo.

${ }^{9}$ Pela fertirrigação, a planta é fertilizada pela água. São inseridos, na água a ser utilizada para irrigação da horta, fertilizantes líquidos ou hidrossolúveis.

${ }^{10}$ Chega a registrar 3.500 horas de sol por ano, média superior a outros estados do Nordeste, como Ceará (3.000 horas de sol por ano).
} 
Um dos entrevistados apontou um peculiar aspecto da produção de petróleo em Mossoró. O empresário, produtor de componentes mecânicos para a indústria petrolífera, afirmou que vem sendo procurado por empresas exploradoras de petróleo na Argentina, interessadas em alguns de seus produtos, o que pode significar a ampliação da importância de bens de capital na pauta de exportações da cidade.

De fato, tal informação não deve ser interpretada como uma tendência, uma vez que, no ano de 2006, foram exportados apenas 7.264 (em US\$ FOB) de bens de capital de um total de 98.157.527 (em US\$ FOB) pela cidade.

A castanha de caju, segundo produto na pauta de exportações - em ordem de valor - de Mossoró, apresenta queda no seu volume exportado no período de janeiro a abril de 2007 em relação ao mesmo período do ano passado. Segundo o Ministério do Desenvolvimento, Indústria e Comércio Exterior, o valor exportado teve variação negativa de 40,53\%.

Os empresários do setor afirmam que as seguidas desvalorizações do dólar perante o real percebidas em 2007 não tornam o mercado externo atraente, de modo que, por hora, atendem preferencialmente o mercado interno e estocam parte da produção para oferecê-la no mercado internacional quando lhes for mais conveniente.

O sal, embora tenha passado por período de crise ${ }^{11}$, figura ainda como importante produto da pauta de exportações mossoroense, sendo o sal marinho a granel o nono colocado na pauta de exportações potiguar (ver Tabela 2).

Os motivos atribuídos à significativa participação da indústria salineira no comércio internacional da cidade são principalmente as características naturais da região e a qualidade atual do sal produzido, conquistada justamente com a imposição do desenvolvimento tecnológico do processo produtivo.

Os entrevistados apontam que, embora a produção do sal tenha se tornado bastante dispendiosa $^{12}$, o setor vem apresentando recuperação e é esperado aumento da produção salineira já para o ano de 2007.

De fato, as expectativas em torno dessas três atividades são boas - ressalvado o caso do petróleo, que, embora tenha, para os entrevistados, amplas perspectivas de crescimento da produção, provavelmente não será mais exportado como produto bruto pelo estado.

A fruticultura - principalmente o melão - já dá sinais de crescimento concretos em $2007^{13}$, o que justifica o fato de ser alvo de expectativas otimistas por parte de nove entrevistados. Um dos entrevistados, justamente por ser produtor de melão, se mostrou receoso quanto à desvalorização cambial do dólar em relação ao real. Para ele, se o dólar chegar a valer menos de R $\$ 1,80$, o setor não vai ter condições de explorar o mercado externo.

\footnotetext{
${ }^{11}$ Motivada, como visto anteriormente, principalmente pela concorrência do sal chileno.

12 Pela necessidade de melhoramento tecnológico do processo de produção, em virtude de exigência da demanda, notadamente a do mercado externo. Note-se que o sal, por ser uma "commodity", tem preço rígido no mercado internacional, não podendo agregar custos com processo produtivo.

${ }^{13}$ De acordo com a Secretaria de Desenvolvimento do estado do Rio Grande do Norte, as exportações de melão cresceram $33,8 \%$ (em valor) no período de janeiro a maio quando comparadas ao mesmo período do ano anterior.
} 
Apenas um dos entrevistados apontou a cera de carnaúba como uma das atividades que se destacam no comércio exterior do município. Na verdade, a cera de carnaúba perdeu muito de sua utilidade com o surgimento de outras matérias-primas e com o desenvolvimento tecnológico das indústrias que dela se serviam, como já abordado anteriormente.

No entanto, aparece na pauta de exportações da cidade com relativa importância, conforme se percebe pela avaliação da Tabela 4. Com efeito, a produção da cera de carnaúba passa por período de reaquecimento, tendo em vista suas novas aplicações industriais ${ }^{14}$, tendo apresentado crescimento de impressionantes $267,64 \%$ no valor exportado de janeiro a abril de 2007 em relação ao mesmo período de 2006, de acordo com o Ministério do Desenvolvimento, Indústria e Comércio Exterior.

Os entrevistados também foram unânimes quanto à necessidade de ampliação de atividades voltadas para o mercado externo.

Dentre as razões apontadas para essa necessidade, destacam-se a perspectiva de maior lucratividade, a exploração de potencialidades ainda subexploradas (como artesanato), a eventual necessidade de buscar novos mercados em virtude de crise interna e a possibilidade de desenvolvimento econômico e social da região.

Os gestores públicos apontaram, ainda, que a diversificação de atividades é importante por passar o status ${ }^{15}$, geralmente associado aos exportadores, de produtos de alta qualidade.

Para que seja realizada a pretendida ampliação das atividades destinadas ao mercado externo, cinco empresários destacaram a necessidade urgente de serem feitos investimentos em infra-estrutura logística. Um gestor público, assim como todos os empresários, sugeriram a ampliação de vantagens fiscais aos exportadores. Quatro dos entrevistados lembraram da importância da divulgação dos produtos, que, em sua visão, deve ser realizada através da participação em feiras internacionais e viabilizada pela administração pública.

Há de ser destacada também a preocupação do empresariado com a falta de mão-de-obra qualificada. Cinco deles entendem que a diversificação das atividades voltadas ao mercado externo, bem como o aprimoramento das atividades já consolidadas, deve necessariamente contar com a ampliação do suporte técnico oferecido por entidades como o Sebrae, capazes de qualificar a mão-de-obra.

Sobre o problema logístico do estado, os fruticultores enfatizaram o péssimo estado do modal rodoviário que escoa a produção de frutas do estado. Segundo os produtores, as cargas sofrem constantes avarias decorrentes das trepidações ocorridas no transporte das frutas pelas esburacadas estradas de barro. A perda oriunda dos impactos sofridos pelas frutas chega à ordem de $8 \%$ dos melões transportados, rejeitados pelo exigente mercado externo.

\footnotetext{
14 De acordo com a Secretaria da Ciência e Tecnologia do Estado do Ceará, a cera de carnaúba tem atualmente várias utilidades nas indústrias farmacêutica, cosmética, eletrônica, dentre outras. A secretaria informa também que os principais importadores da cera são E.U.A., Alemanha, Japão e Países Baixos.

${ }^{15}$ Minervini (2001, p. 6) aponta alguns motivos para a inserção da empresa no mercado internacional, dentre eles estão o melhoramento da imagem com fornecedores, bancos e clientes; possibilidade de preços mais rentáveis; e dificuldades de vendas no mercado interno.
} 
Sete entrevistados entendem que há um direcionamento da cidade para a inserção de outras atividades voltadas para o comércio exterior. Todos eles citaram a apicultura como atividade mais promissora no que se refere a comércio internacional. Três incluíram também a indústria de cerâmica como potencial exportadora.

Com efeito, a indústria de cerâmica começa a se consolidar em Mossoró. De acordo com os gestores públicos entrevistados, a intenção, no âmbito municipal, é criar um Pólo Cerâmico em Distrito Industrial da cidade. Os entrevistados apontam a abundância de matéria-prima ${ }^{16}$ como principal fator atrativo para o setor, além de ressaltar os incentivos dados por meio do Programa de Desenvolvimento Econômico ${ }^{17}$ (PRODEM).

A apicultura, por sua vez, é vista como uma atividade de grande potencial na região. Como visto na Tabela 4, o mel aparece em 2006 como o sétimo produto exportado mais importante em termos de valor. Os representantes do setor destacam a importância do Sebrae, que presta vasto apoio técnico aos apicultores.

A entidade recentemente firmou convênio com a prefeitura de Mossoró e com a Universidade Federal Rural do Semi-Árido (Ufersa) para a implementação do Projeto Abelha Rainha, pelo qual, em parceria com pesquisadores da Universidade de São Paulo (USP), serão desenvolvidas pesquisas no sentido de desenvolver a reprodução de abelhas rainhas por meio de inseminação artificial e aumentar a qualidade do mel produzido no estado. Para os produtores locais, o projeto pode proporcionar ao estado a condição de referência nacional de qualidade do mel.

As razões apontadas para justificar as altas expectativas em torno da apicultura no estado se baseiam na atual conjuntura internacional, com a taxação do mel chinês por parte dos E.U.A. - principal importador do mel brasileiro -, a perda (ainda não explicada) de enxames pelos produtores americanos e o sucesso de missão da União Européia ${ }^{18}$ que veio ao Brasil verificar a implantação do PNCR (Programa Nacional de Controle de Resíduos), o que pode significar a reabertura do mercado europeu ao mel brasileiro.

Com efeito, percebe-se que o mel, cujas exportações iniciaram-se na cidade na segunda metade de 2006, vem adquirindo importância na pauta de exportações mossoroense, já aparecendo como sétimo produto mais exportado pelo município em 2006 (Tabela 4).

O camarão também chegou a ser citado por um dos entrevistados, entretanto, não apresenta mais relevância no comércio internacional de Mossoró por estar enfrentando grave crise ${ }^{19}$.

\footnotetext{
${ }^{16}$ Segundo informações colhidas do site da Câmara dos Vereadores de Mossoró, há ocorrência na região de mineral de quartzo, areia quartzosa industrial, argila para cerâmica vermelha e marga domilítica, além da abundância de gás natural, utilizado como insumo de produção pela indústria.

${ }^{17}$ De acordo com a lei municipal 1.502/2000, o programa tem como objetivo promover o desenvolvimento econômico e sustentável de Mossoró, por meio do estímulo a implantação, expansão, modernização e reativação de empreendimentos produtivos. Esse estímulo se dá com a concessão de incentivos e benefícios financeiros, creditícios, econômicos e de infra-estrutura.

18 Conforme informações veiculadas pelo Sebrae, a União Européia suspendeu as importações de mel brasileiro por não haver, por parte do governo brasileiro, informações satisfatórias que atestem o controle de resíduos químicos na produção nacional. O impasse, todavia, parece estar perto de ser contornado, com a implantação do Programa Nacionalde Controle de Resíduos pelo Ministério da Agricultura, Pecuária e Abastecimento.

19 Segundo a Secretaria de Estado do Meio Ambiente e dos Recursos Hídricos, crise esta oriunda principalmente de taxação imposta ao camarão brasileiro pelo governo dos E.U.A., da queda brusca do dólar, do surgimento de pragas e da falta de apoio governamental, como visto anteriormente.
} 
Um dos gestores públicos apontou também o potencial do estado para a produção de biodiesel, ressaltando a importância dessa atividade ser fomentada pelo governo estadual.

Os entrevistados que não vêem um direcionamento na cidade para a inserção de outras atividades no comércio internacional fundamentaram tal posicionamento principalmente pela falta de cultura exportadora e pela dificuldade de financiamento para a iniciativa privada de modo geral.

Quando questionados sobre a avaliação que faziam sobre a administração municipal no tocante à economia mossoroense de modo geral, os getores da iniciativa privada entrevistados deram opiniões divergentes.

Por um lado, três deles se mostraram descontentes com a administração, classificando-a como "regular" ou "insatisfatória". Os motivos apresentados para tal opinião foram principalmente a falta de incentivos fiscais - principalmente para médias e grandes empresas locais - e a dificuldade de conseguir financiamento.

Os fruticultores destacam que só é possível sustentar sua operação em virtude de receberem dos seus compradores parte do pagamento (30\%) adiantado ${ }^{20}$, recebendo o restante $(70 \%)$ à vista. Em sua opinião, se o governo viabilizasse o financiamento para o setor, poderia haver um grande crescimento da produção, capaz de melhor atender à abundante demanda.

Além disso, afirmam que a administração municipal deveria ser mais eficiente na atração de indústrias produtoras de insumos. Para os fruticultores, a cidade deveria ter um parque industrial mais diversificado, capaz de fornecer os insumos que a fruticultura necessita por custos menores.

Os representantes do setor de fruticultura afirmam, ainda, que não há vontade política, tanto no âmbito municipal quanto no estadual, para apoiar devidamente o setor e atender suas principais reinvindicações.

Para os empresários do setor salineiro, além da falta de incentivos fiscais e de financiamento, o governo interfere negativamente na medida em que intensifica a fiscalização e as exigências fitossanitárias sobre a indústria, aumentando seus custos de produção.

Os outros entrevistados, que consideraram a administração municipal "boa" ou "excelente", ressaltaram os investimentos em infra-estrutura e principalmente a ampla divulgação da cidade. Para os entrevistados, os esforços para realizar e divulgar os eventos culturais e econômicos de Mossoró beneficiam diretamente a economia da cidade, atraindo mais investimentos da iniciativa privada.

Os empresários citaram alguns eventos ${ }^{21}$ como fundamentais para a divulgação da cidade, dentre eles a Feira do Bode, em julho, a Feira Industrial e Comercial do Oeste (FICRO) e a

\footnotetext{
${ }^{20}$ Maia (2003, p. 273) aponta como principais modalidades de pagamento no comércio internacional a remessa antecipada, a remessa sem saque, a cobrança e a carta de crédito, destacando que a remessa antecipada é adotada principalmente quando é necessário que o importador financie a produção por parte do exportador.

${ }^{21}$ Todos constantes no calendário de eventos disponível no site da prefeitura de Mossoró.
} 
Expofruit, em agosto, além de eventos culturais, como o Mossoró Cidade Junina, em junho, e o Chuva de Bala no País de Mossoró.

No que se refere a ações específicas de fomento ao comércio internacional, o desempenho da administração municipal é bem mais modesto, na visão dos entrevistados. Apenas um considerou "excelente" a atuação do governo local nesse quesito, enquanto os demais variaram as respostas entre "regular" e "insatisfatória".

Embora admitam que a administração municipal se preocupe com o incentivo aos produtores em participarem de feiras internacionais, os entrevistados cobram uma postura mais agressiva por parte do governo local, bem como oferecimento de incentivos fiscais e maior suporte técnico à iniciativa privada.

Quando questionados sobre as ações governamentais que podem ser destacadas como fomentadoras do comércio exterior e sobre os projetos futuros para o comércio internacional, os gestores públicos citaram algumas ações, como os eventos ocorridos na cidade (em especial a FICRO, a Expofruit e um Encontro de Comércio Exterior realizado em 2005), a participação em feiras internacionais e a construção da "Estrada do Melão"22, reinvindicação antiga dos fruticultores e agora em fase de conclusão do projeto.

Os gestores públicos afirmaram ainda que os governos municipal e estadual têm como objetivos investir na capacitação profissional da mão-de-obra, embora não haja nenhum projeto nesse sentido para atividades relativas ao comércio exterior.

De fato, não se percebem políticas públicas ${ }^{23}$ de fomento ao comércio internacional bem definidas.

A receptividade das ações governamentais pela iniciativa privada é considerada moderada por dois e alta por um dos gestores públicos entrevistados. Os gestores apontam que é sabido que os empresários se mostram insatisfeitos em alguns aspectos, mas indicam a relação de parceria existente entre as duas esferas.

Interessa notar que os gestores públicos entendem ser imprescindível o fortalecimento dos setores da economia no sentido de serem representados de maneira mais consistente, de forma que, assim, possam ter suas reinvindicações atendidas mais rapidamente.

Quando questionados se havia a necessidade de alguma mudança no direcionamento da iniciativa privada sobre a inserção no comércio internacional, todos os entrevistados responderam positivamente.

Os principais motivos apontados para a imprescindibilidade de mudanças foram as exigências do mercado externo quanto à qualidade do produto e a necessidade de divulgação dos produtos locais.

\footnotetext{
${ }^{22} \mathrm{O}$ projeto de construir uma rodovia asfaltada ligando várias áreas produtoras de melão do oeste potiguar (desde Tibau à "Estrada do Cajueiro", que liga o Rio Grande do Norte ao Ceará) integra, segundo veiculado pelo Departamento Estadual de Imprensa, a chamada Agenda do Crescimento, programa de investimentos do Governo do Estado para os próximos quatro anos.

${ }^{23}$ Para Bucci (2002, p. 241), políticas públicas podem ser conceituadas como "programas de ação governamental visando a coordenar os meios à disposição do Estado e as atividades privadas, para a realização de objetivos socialmente relevantes e politicamente determinados".
} 
Para atender às demandas externas relativas à qualidade dos produtos, os entrevistados sugeriram a ampliação do suporte técnico oferecido pelo governo, investimentos em novas técnicas e tecnologias, e a capacitação da mão-de-obra por parte da administração pública. Sugeriram, ainda, a intensificação da participação em feiras internacionais como principal medida para a divulgação dos produtos.

Sete dos dez entrevistados afirmaram ver Mossoró atualmente como uma "cidade global". Os que assim se manifestaram entendem que a cidade participa intensamente de processos globais e polariza as atividades econômicas da região em que se encontra.

Todos os dez entrevistados têm perspectivas otimistas para os próximos anos do comércio internacional mossoroense. Embora haja alguma preocupação quanto às variações cambiais do dólar, todos acreditam, de modo geral, que as atividades que já têm uma boa participação no comércio internacional tendem a crescer. Ressaltam também o potencial de crescimento daquelas que estão surgindo.

Três entrevistados lembraram o fato de Mossoró ser, desde 2006, o principal pólo exportador do estado (Tabela 3) e opinaram pela perpetuação dessa situação, principalmente pelas perspectivas de crescimento das exportações de fruticultura e castanha de caju. Note-se que, como visto anteriormente, é fundamental para estes dois setores que a cotação do dólar volte a subir ou, pelo menos, se mantenha estável.

\section{CONSIDERAÇÕES FINAIS}

O atual desempenho de Mossoró no comércio internacional se deve, de acordo com o que se mostrou acima, principalmente a um número restrito de produtos. Em termos quantitativos, a castanha, o melão e alguns outros produtos da fruticultura irrigada são preponderantes na pauta de exportações da cidade.

O grande desenvolvimento dessas atividades na região está intimimente ligado a ações governamentais $^{24}$ realizadas no decorrer da segunda metade do século passado que, ainda que não fossem esses exatamente os resultados esperados, conseguiram fomentar a fruticultura irrigada local.

Ao lado da iniciativa pública, há que se destacar, também, os investimentos feitos pela iniciativa privada, que possibilitaram o desenvolvimento de grandes empresas e a grande modernização da indústria, fator que possibilitou grande evolução dos produtos em termos de qualidade.

Deve-se ressaltar, ainda, a grande divulgação da cidade por parte da administração municipal como fator impulsionador da economia mossoroense. É possível concluir, com base nos resultados obtidos, que a divulgação, não só pela realização de feiras na cidade e participação de feiras no exterior, mas também a divulgação de eventos culturais tem contribuído diretamente para a promoção da economia local de um modo geral.

\footnotetext{
${ }^{24}$ Notadamente os diversos programas implantados desde meados do século passado com o intuito inicial de beneficiar um grande número de pequenos produtores.
} 
Como visto anteriormente, Mossoró é a cidade que mais exporta no Rio Grande do Norte, fato que a leva ao patamar de mais importante pólo exportador do estado desde 2006.

Em nível nacional, contudo, a situação é bem diferente. Pode-se perceber, conforme dito em momento anterior, que a cidade representa uma parcela muito pouco significativa do total das exportações brasileiras. Todavia, ainda que as exportações mossoroenses consistam em valor irrisório perante o total exportado pelo país, a cidade se destaca nas exportações de determinados produtos, notadamente o sal, o melão, a banana e a castanha de caju.

Mossoró contribui incisivamente para que o Rio Grande do Norte seja o estado que mais exporta sal, melão e banana do Brasil, sendo o segundo maior exportador de castanha de caju.

Desse modo, Mossoró, mesmo não sendo de grande importância em termos quantitativos para a economia nacional, pode ser vista como uma cidade que explora bem seus potenciais.

$\mathrm{O}$ momento por que passam as principais atividades exportadoras do município merece alguns comentários.

O sal, embora esteja ainda em queda no estado, apresenta, na cidade, melhoras substanciais em termos de exportação e as expectativas em relação a essa atividade tanto no mercado interno quanto no externo são otimistas.

Há de se apontar, também, a entrada da apicultura no contexto do comércio internacional mossoroense. A despeito de ser ainda uma atividade incipiente, já consta na pauta de exportações da cidade como um dos principais produtos e é vista com excelentes perspectivas por parte dos gestores entrevistados.

De um modo geral, percebe-se, pelos resultados obtidos, que há deveras uma perspectiva otimista em relação ao comércio internacional de Mossoró, principalmente em relação às atividades tradicionais da economia da cidade.

Todavia, não se pode deixar de ressalvar que o crescimento não só da cidade, mas do estado, depende necessariamente de alguns fatores fundamentais para o aumento da competitividade local no comércio exterior. Deve-se destacar, diante dos dados obtidos com esta pesquisa, que não se pode prescindir de investimentos em logística e qualificação de mão-de-obra.

Há de ser feita menção também à necessidade de uma diversificação das atividades voltadas ao comércio internacional de Mossoró, que passa indispensavelmente por uma mudança de postura por parte do empresariado, no sentido de desenvolverem uma cultura exportadora.

Devem-se apontar, ainda, algumas das principais reinvindicações dos gestores privados, como a necessidade de viabilização de maiores fontes de financiamento, a presença de profissionais com maior qualificação técnica em algumas áreas da gestão pública, a manutenção de um patamar de desvalorização do real perante o dólar e maiores incentivos fiscais aos exportadores. 
Por fim, tem-se como principal conclusão o fato de Mossoró desempenhar, no âmbito estadual, o papel de maior cidade exportadora.

Conclui-se, de acordo com informações abordadas anteriormente, que Mossoró pode ser enquadrada no conceito de "cidade global", tendo em vista o papel que a cidade exerce no âmbito regional, ao centralizar atividades e influenciar intensamente as economias das cidades próximas.

No âmbito nacional, embora não seja tão importante em termos quantitativos, deve-se salientar o bom aproveitamento de suas potencialidades e o notável destaque da cidade em alguns produtos específicos, como a castanha de caju e o melão.

\section{REFERÊNCIAS BIBLIOGRÁFICAS}

1. BRASIL. Ministério do Desenvolvimento da Indústria e Comércio Exterior. Balança comercial por município. Disponível em: <http://www.mdic.gov.br $\rangle$. Acesso em: 10 jun 2007.

2. BRUM, Argemiro J. O desenvolvimento econômico brasileiro. 23 ed. Rio de Janeiro: Editora Vozes, 2003.

3. BUCCI, Maria P. D. Direito administrativo e políticas públicas. São Paulo: Saraiva, 2002.

4. CEARÁ. Secretaria da Ciência e Tecnologia. Disponível em <http://www.sct.ce.gov.br>. Acesso em: 15 jun 2007.

5. CHESNAIS, François. A mundialização do capital. Traduzido por Silvana Finzi Foá. São Paulo: Xamã, 1996. Tradução de: La Mondialisation du Capital.

6. COMITÊ Executivo de Fitossanidade do Rio Grande do Norte. Disponível em <http://www.coex.com.br>. Acesso em: 08 jun 2007.

7. RIO GRANDE DO NORTE. Departamento Estadual de Imprensa. Disponível em <http://www.dei.rn.gov.br>. Acesso em: 15 jun 2007.

8. ÍNDICE fundamental do Direito. Disponível em <http://www.dji.com.br>. Acesso em: 17 jan 2007.

9. IRRIGOTEC. Disponível em <http://www.irrigotec.com.br>. Acesso em 01 jun 2007.

10. LEVY, Evelyn. Democracia nas cidades globais: um estudo sobre Londres e São Paulo. São Paulo: Studio Nobel, 1997.

11. LUZ, Rodrigo. Relações econômicas internacionais: teoria e questões. Rio de Janeiro: Editora Campus, 2006.

12. MAIA, Jayme de M. Economia internacional e comércio exterior. 8 ed. São Paulo: Editora Atlas, 2003.

13. MINERVINI, Nicola. O exportador: ferramentas para atuar com sucesso nos mercados internacionais. 3 ed. São Paulo: Makron Books, 2001.

14. MOSSORÓ. Câmara Municipal. Disponível em <http://www.msr.interlegis.gov.br>. Acesso em: 10 jun 2007. 
15. MOSSORÓ. Prefeitura Municipal. Disponível em <http://www.mossoro.rn.gov.br>. Acesso em: 10 jun 2007.

16. ROCHA, Aristotelina P. Barreto. Expansão urbana de Mossoró: período de 1980 a 2004. Natal: Coleção Mossoroense, 2005.

17. SASSEN, Saskia. As cidades na economia mundial. Traduzido por Carlos Eugênio Marcondes de Moura. São Paulo: Studio Nobel, 1998. Tradução de: Cities in a World Economy.

18. RIO GRANDE DO NORTE. Secretaria de Estado de Desenvolvimento Econômico. Disponível em <http://www.sedec.rn.gov.br>. Acesso em: 15 jun 2007.

19. SOUTO, Edith F.; FERNANDES, Carlos H. C. A importância da indústria salineira do Rio Grande do Norte para a economia brasileira. Mossoró: Coleção Mossoroense, 2005.

20. THORSTENSEN, Vera. Organização Mundial do Comércio - OMC: as regras do comércio internacional e a nova rodada de negociações multilaterais. São Paulo: Aduaneiras, 2001.

21. UNIVERSIDADE FEDERAL RURAL DO SEMI-ÁRIDO. Disponível em <http://www.esam.com.br>. Acesso em: 08 jun 2007. 